American Journal of Economics and Business Administration 3 (2): 425-429, 2011

ISSN 1945-5488

(C) 2011 Science Publications

\title{
Investigating the Relationship between Organizational Social Capital and Service Quality in Teaching Hospitals
}

\author{
${ }^{1}$ Fereshteh Farzianpour, ${ }^{2}$ Abass Rahimi Fouroshani, \\ ${ }^{3}$ Reza Gholi Vahidi, ${ }^{1}$ Mohamad Arab, ${ }^{1}$ Amjad Mohamadi \\ ${ }^{1}$ Department of Health Management and Economics, \\ ${ }^{2}$ Department of Epidemiology and Statistic, \\ School of Public Health, Tehran University of Medical Sciences, Tehran, Iran \\ ${ }^{3}$ Department of Health Management and Economics, \\ Tbriz of University of Medical Sciences Tbriz, Iran
}

\begin{abstract}
Problem statement: In modern age, the service quality and sensitivity towards better qualified service are among the priorities of the global community. Quality is defined as the customer's desire and the customer's perceptions and expectations constitute the key factor determining quality. The issue of quality is particularly important in healthcare service. Nowadays, alongside the human, financial and economic capitals, a new form of capital entitled social capital is being utilized. Social capital may influence the service quality. Facilitating science and improving team work and organizational commitment would probably translate into better quality of products and social capital encompasses all these issues. Approach: This is a cross-sectional, descriptive-analytic study conducted in educational hospitals of Tabriz, Iran in 2010. The target community consists of workers working in educational hospitals of Tabriz and patients referring to these hospitals. A total of 320 workers and 320 patients were selected for the study. Our data collection tool consisted of two questionnaires which were distributed among the participants after their validity and reliability were established. Once the questionnaires were completed, the statistical coefficients relating to the types of variables (t-test, Pearson correlation coefficient and analysis of variance) were calculated and analyzed using SPSS software version 16. Results: Our findings indicate that there is a significant, positive relationship between organizational social capital and the service quality from the patients' point of view, with the correlation between the two variables on a strong level $(r=0.6, p<0.001)$. Regression analysis results indicate that the five dimensions of social capital account for $0.88 \%$ of the variance in service quality equation and the variable relationship among workers in social networks is the most influential factor on service quality in the study population; this factor accounts for $0.59 \%$ of the variation in service quality. Conclusion: The existence of a significant relationship between the dimensions of social capital and service quality highlights the importance of social capital of workers in the organization.
\end{abstract}

Key words: Organizational social capital, service quality, educational hospitals, customer's perceptions, statistical coefficients, significant relationship, regression analysis

\section{INTRODUCTION}

Nowadays, manufacturing and service organizations use customer satisfaction as a standard for evaluating quality, since customer satisfaction is a necessity for global competition. Quality management provides an organized attention to understand customer's expectations in order to surpass them and thus satisfy him. Service quality may be defined as an indicator of satisfaction for any service provided (Oliverira, 2009). Quality has been defined as customer's desire and the customer's perceptions and expectations constitute the key factor determining quality (Bernardes, 2010). Satisfaction with services may provide valuable data regarding the interpersonal aspects of healthcare, as well as the mutual relationship

Corresponding Author: Fereshteh Farzianpour, Department of Health Management and Economics, School of Public Health, Tehran University of Medical Sciences Tehran, Iran Tel:+98(21)44648943 Fax: 98(21)88989129 
between provider and customer and customer's perceptions (Fabio, 2005; Huang and Wang, 2011). One factor which, we believe, may affect the service quality in hospitals greatly is the state of social capital of workers in the organization. This concept was first introduced by (Mirfardi, 2011) entered this concept into North American politics. His efforts were pursued by Putnam in Europe and the theory of social capital was developed with the theories of Coleman and Putman (Samimi et al., 2009). Up to now, the relationships between social capital and numerous variables, such as quality of life (Nillson et al., 2006) trust, awareness and occupational satisfaction (Ommen et al., 2009), improved wellbeing and diminished poverty (Woolcock and Narayan, 2006), health and quality of life in workplace (Chen et al., 2010) have been demonstrated in many studies. Social capital creates collaboration, commitment, data sharing and trust. It also improves true cooperation in an organization which leads to the success and efficiency of workers. Individuals, social groups and organizations require communication and social relations in order to achieve their objectives (Turkson and Wang, 2009). Managers and others who succeed in establishing social capital in their organization pave their way to occupational and organizational success. States that social relations in social capital have predictable capacities and may create values. Unlike human capitals and traditional assets of an organization, social capital is the exclusive result of significant social relations in which people have invested over time (Mohammadian, 2009). In the past, social capital did not use to be an indispensable merit for an organization; however, the current rapid changes in information technology, the ever-growing need for information and education, requirements of creativity and innovations, constant advances, shift towards designing flexible organizational structures, relationships between organizations and the network of customers, providers and rivals mandate organization leaders to create social capital as a distinct organizational merit (Aspin, 2004; Carifio and Perla, 2010). Through identification of the dimensions of social capital, organizations acquire a better understanding of the pattern of interpersonal and group interactions and thus, they can use it to lead their organizational systems in a more efficient way (Yahaya et al., 2009). Therefore, the objective of this study is to cover the title using theories of service quality and social capital in order to investigate the relationship between dimensions of social capital and those of service quality through a survey with questionnaires, determine the current social capital and its relationship with the services provided and offer approaches for improving it.

Considering the above, the major scope of this study will be as follows:

- What is the level of organizational social capital of workers in hospitals belonging to Tabriz University of Medical Sciences

- What is the service quality provided by hospitals belonging to Tabriz University of Medical Sciences from the customers' point of view

- Is there a significant relationship between organizational social capital and service quality

\section{MATERIALS AND METHODS}

This is a cross-sectional, descriptive-analytic study on all workers and patients referring to educational hospitals of Tabriz, including Emam Reza, Shohada, Razi, Shahid Madani, Alzahra, Alavi, Nikukari, Kudakan, Sina and Taleghani Hospitals over a period of one month. The overall number of workers in 2010 and the overall population of patients referring to these hospitals in one month are 4658 and 14604, respectively. The most important objective of this study is to investigate the relationship between the score of organizational social capital and the score of service quality for hospitals of Tabriz; since this relationship is studied using regression analysis and correlation coefficient, sample size was determined is such a way that correlation coefficients of 0.2 or higher are statistically significant with confidence interval of $95 \%$ and test power of $90 \%$. Thus, the sample size for workers and patients was calculated to be 320 .

Considering the nature of the subject and the population under study (variances among hospitals, workers' occupational class and gender), we used proportionate stratified sampling in the present study. Data collection tool consisted of two questionnaires pertaining to service quality and social capital. The questionnaire of organizational social capital included 20 multiple choice questions (five choices) in five dimensions (social participation, participation in social networks, social trust, perception of social support and perception of environment), with a Cronbach's $\alpha$ of 0.81 for reliability. At first, all the questions of this index were computed with SPSS software to yield an interval index. The minimum and maximum scores of social capital were calculated to be 20 and 100 , respectively. The questionnaire of service quality 
included 18 questions in seven dimensions (assurance, empathy, tangibles, responsiveness, input sufficiency, facilitating payments and communications) with a Cranach's $\alpha$ of 0.80 for reliability. The scoring was similar to social capital. The minimum and maximum scores of service quality were calculated to be 18 and 90, respectively. We used descriptive statistics (including tables and graphs, indices of central tendency and dispersion, frequencies) and inferential statistics (t-test, mean differences, Pearson's correlation coefficient, analysis of variance) to analyze our data. The statistical analyses were performed with the SPSS software package version 16.

\section{RESULTS}

Descriptive results: Out of the 320 hospital workers, $179(55.9 \%)$ were men and $141(44.1 \%)$ were women, while out of the 320 patients, $50 \%$ were men and $50 \%$ were women. The self-declared level of education was post-high school diploma for $19.1 \%$, bachelor's degree for $44.4 \%$ and master's degree or higher for $36.6 \%$ of the hospital workers. Out of the 320 patients, $3.1 \%$ were illiterate, $26.2 \%$ were below high school diploma, $19.7 \%$ had high school diploma, $27.5 \%$ had post-high school diploma, $13.4 \%$ had bachelor's degree and $10 \%$ had master's degree or higher.

The findings indicate that the organizational social capital of the workers in study has a mean of 54.4 with a standard deviation of 4.25 . Furthermore, from the patients' point of view, the service quality in hospitals of Tabriz has a mean of 49.03 with a standard deviation of 3.22.

The results of Pearson's $r$ test on the relationship between the dimensions of social capital and service quality indicate that the variables of social participation, mutual action and trust, social support, relationships in social networks and perception of environment are significantly interrelated with correlation coefficients of $0.23,0.4,0.6,0.69$ and 0.22 , respectively $(\mathrm{p}<0.001)$. It may de deduced that there is an average correlation between the dimensions of social capital and service quality and there is a direct correlation between social capital and service quality (Table 1).

From the patients' point of view, the level of organizational social capital of workers was significantly correlated with the service quality of hospitals; there was a strong $(\mathrm{p}<0.001, \mathrm{r}=0.6)$, linear correlation observed between the two variables. Thus, the primary hypothesis of the study is confirmed, indicating that changes in the level of organizational social capital of workers cause fluctuations in the dependent variable (service quality). In other words, increasing the level of organizational social capital of workers enhances service quality.

Fitting the model predicting the impact of social capital on service quality in hospitals of Tabriz: In order to fit the predicting model, the variables of organizational social capital (social participation, relationships in social networks, perception of social support, social trust and perception of environment) which were measured on an interval level entered the stepwise multiple regression analysis as independent variables.

The results of the regression analysis of factors predicting service quality indicate that all the independent variables which entered the regression model remained in the regression equation and they account for about $0.88 \%$ of the changes in the dependent variable of our study.

Considering the results of regression analysis, it may be stated that the multiple correlation coefficient is equal to 0.94 (M.R $=0.94)$ and its square, i.e. the coefficient of determination, equals 0.88 . Therefore, the variables of social participation, relationships in social networks, perception of social support, social trust and perception of environment account for $0.88 \%$ of variance of service quality in the equation purely. Other variances are accounted for by other unidentified, external factors which have not been dealt with in this study. In this model, the most important factor, which is more influential than others, is the variable of workers' relationships in social networks. The final model of multiple regression analysis in our study is as follows the regression coefficients and standard error values of each coefficient are given in Table 2:

Service quality $=($ social networks $)($ se $=1.78)+($ social trust $)(\mathrm{se}=0.44)+($ perception of environment $)(\mathrm{se}=$ $0.13)+($ social support $)($ se $\quad=\quad 0.114)+($ social participation $)(\mathrm{se}=0.26)$

Table 1: Correlation test of the relationship between dimensions of social capital and service quality

\begin{tabular}{lll}
\hline & Service quality & \\
& Correlation & $\begin{array}{l}\text { Significance } \\
\text { level }\end{array}$ \\
Dimensions of social capital & coefficient & $\mathrm{P}<0.001$ \\
\hline Social Participation & 0.23 & $\mathrm{P}<0.001$ \\
Social Trust & 0.4 & $\mathrm{P}<0.001$ \\
Social Support & 0.6 & $\mathrm{P}<0.001$ \\
Relationships in Social Networks & 0.69 & $\mathrm{P}<0.001$ \\
Perception of Environment & 0.22 & $\mathrm{P}<0.001$ \\
Social Capital & 0.6 &
\end{tabular}


Am. J. of Economics and Business Administration 3 (2): 425-429, 2011

Table 2: Statistics of independent variables in the regression model (variables remaining in the model)

\begin{tabular}{lllll}
\hline Variable & $\mathrm{B}$ & Std.B & Beta & P value \\
\hline Y-Intercept & 11.123 & 653 & - & $\mathrm{P}<0.001$ \\
Workers' relationship in social networks & 1.781 & 0.042 & 0.89 & $\mathrm{P}<0.001$ \\
Workers' mutual action and social support & 0.443 & 0.04 & 0.242 & $\mathrm{P}<0.001$ \\
Workers' social participation & 0.259 & 0.033 & 0.181 & $\mathrm{P}<0.001$ \\
Perception of social support & 0.114 & 0.026 & 0.091 & $\mathrm{P}<0.001$ \\
Workers' perception of environment & 0.132 & 0.044 & 0.06 & $\mathrm{P}<0.001$ \\
\hline
\end{tabular}

The results of the table of analysis of variance pertaining to the regression analysis indicates that the suggested regression model in this study is acceptable and it may demonstrate the relationship between social capital and service quality well $(\mathrm{p}<0.001, \mathrm{f}=478.1)$.

\section{DISCUSSION}

The objective of this study was to determine the relationship between the social capital of workers employed in hospitals of Tabriz with the service quality from the viewpoints of patients or their companions. As the results indicate, all five dimensions of social capital were significantly related to service quality of hospitals. The presence of a significant relationship between dimensions of social capital and service quality highlights the importance of workers' social capital in an organization.

Different studies indicate that access to information, benefitting from counsel, advices and suggestions, emotional encouragement, emotional support, financial aids are resources and blessings that result from social interactions and enable people to accomplish more in different domains of their lives and careers (Arayesh and Hosseini, 2010).

In fact, the bonds among members of a network serve as a valuable resource to fulfill the objectives of an organization through creation of norms and mutual trust, strengthening reciprocal relations and facilitating cooperation and communication while reinforcing the data about the reliability of other individuals, all of which influene service quality.

One major influential factor of service quality is the mutual action and social trust of workers. The most important benefit of mutual action is reinforcing trust, reducing the cost of deals and facilitating cooperation which manifests as cooperation with the patient and providing service for him. Putnam believes the norms of mutual action to be among the most generative constituents of social capital; he states that groups and societies which abide by these norms will efficiently overcome opportunism and other challenges of teamwork. Trust facilitates group participation and moral commitments and higher levels of trust in a society raise the chance of cooperation and collection action, while this cooperation creates trust in its turn.

\section{CONCLUSION}

In general, social capital exerts powerful influences on many aspects of individuals' lives. Some of these influences include increased longevity, improved educational achievements, equal levels of income, enhanced wellbeing for children with attenuated child abuse, diminished bureaucratic corruption, more efficient function of governmental organization and better economic function through increased trust and decreased cost of business deals.

Improving the workers' capabilities may be achieved through reinforcement and enhancement of social capital in organizations using the workers' potentials which are not fully used now (Aspin, 2004). Some achievements resulting from employing and reinforcing social capital in organizations include:

- Fulfilling customer satisfactions and improving it

- Adjusting with market requirements

- Improving occupational satisfaction in workers

- Improving the feeling of belonging, participation and responsibility in workers

- Shifting the attitude from obligation to free will

- Improved commitment of workers and enhanced service quality

- Improved communication of workers with managers and supervisors

- Reducing operational costs and improving the profits of the organization

- Improving the efficiency of decision-making

- Continuous improvement of the organization with improved efficiency

- Innovations and improved use of brainwork

Many studies indicate that if human interaction among the workforce take place comfortably and based on trust, workers will tend to perform with maximum effort (Sharon, 2005).

Recommendations: The findings of this study indicate workers' social capital to have a positive relationship with the quality of services provided by hospitals for patients. Thus, the following recommendations may be considered in order to reinforce the factors associated with social capital: 
- We recommend the preparation of settings for workers' collective participation and social trust. Unless the settings of trust are provided, individuals will tend to be more indifferent

- Investment of hospitals in development of organizational social capital through education of effective communications, enhancement of communications and interactions among workers and managers inside and outside the hospital, creating an atmosphere of collaboration, mutual trust and teamwork will all develop and reinforce the organizational social capital and will expedite the hospital's progression towards improved services provided for patients

- Establishing specialized and professional groups and communities in hospitals with voluntary participation of experts, nurses, physicians and paramedics will improve social capital in hospitals

- Arranging recreational and visiting trips to enhance face-to-face relationship, since these relationships create the norm of trust and thus prepare for collective action of members of the organization.

- $\quad$ Provided that the hospital workers feel assured that hospital managers feel responsible for them, will support them in case of problems and are sensitive to their responsiveness to the society and patients, they will have a positive attitude towards their job which will lead to improved confidence and trust and abolishment of suspicion

- Educational procedures are on the most essential approaches for organizations to create social capital. Enrolling individuals in public education courses, particularly the communication classes, will play a pivotal role in raising social capital

\section{REFERENCES}

Mohammadian, A.K., 2009. A shor-term management strategy for improving transit network efficiency. Am. J. Applied Sci., 6: 241-246. DOI: 10.3844/ajassp.2009.241.246

Arayesh, B. and S.J. Hosseini, 2010. Regression analysis of effective factor on people participation in protecting, revitalizing, developing and using renewable natural resources in ilam province from the view of users. Am. J. Agric. Biol. Sci., 5: 228234. DOI: 10.3844/ajabssp.2010.228.234

Aspin, L., 2004. Social Capital and Productivity: How might training affect a company's social capital? Does the literature indicate how this might happen and whether we might expect a significant impact on productivity? Can these effects be measured, Teaching and Learning Research Programme, pp:
1.34 .

http://www.tlrp.org/dspace/handle/123456789/83

Carifio, J. and R.J. Perla, 2010. Towards the decline and fall of radical and educational constructivism (Mark I). Curr. Res. Psychol., 1: 1-15. DOI: 10.3844/crpsp.2010.1.15

Fabio, S., 2005. Does social capital improve labor productivity in small and medium enterprises, forthcoming. Int. J. Manage. Decis. Mak., 1: 29-37. http://www.socialcapitalgateway.org/SabatiniIJMD M.pdf.

Huang, K.-P. and K.Y. Wang, 2011. How guanxi relates to social capital? A psychological perspective. J. Soc. Sci., 7: 120-126. DOI: 10.3844/jssp.2011.120.126

Mirfardi, A., 2011. Trust and its relationship to demographic factors. J. Soc. Sci., 7: 168-174. DOI: 10.3844/jssp.2011.168.174

Nillson, J., 2006. Social capital and quality of life in the old age. J. Aging Health, 18: 419.434. DOI: 10.1177/0898264306286198

Oliverira, O.D.J., 2009. Adaptation and Application of the Servequal Scale in Higher Education. Proceedings of the POMS 20th Annual Conference Orlando, May 1-4, Florida USA., pp: 1-20. http://www.pomsmeetings.org/ConfProceedings/01 1/FullPapers/011-0072.pdf

Ommen, O., E. Driller, T. Kohler, E. Kowalski and N. Ernstmann et al., 2009. The relationship between social capital in hospitals and physician job satisfaction. BMC Health Services Res., 9: 81-89. DOI: 10.1186/1472-6963-9-81

Samimi, A., H.Z. Aashtiani and A.K. Mohammadian, 2009. A shor-term management strategy for improving transit network efficiency. Am. J. Applied Sci., 6: 241-246. DOI: 10.3844/ajassp.2009.241.246

Sharon, T., 2005. Social capital and gender in work place. J. Manage. Dev., 24: 34-44. DOI: $10.1108 / 02621710510572335$

Turkson, A.J. and X.J. Wang, 2009. Statistical analysis of the risk factors of the major epidemic disease among residents of Sekondi-Takoradi Metropolis (STMA). J. Math. Stat., 5: 146-151. DOI: 10.3844/jmssp.2009.146.151

Woolcock, M. and D. Narayan, 2006. Social capital and its implications for theory development. research and policy. World Bank Res Obs, 15: 225-249. DOI: 10.1093/wbro/15.2.225

Yahaya, A., J. Ramli, S. Hashim, M.A. Ibrahim and Z. Zakaria, 2009. Analysis of students with psychiatric disabilities in higher education. J. Soc. Sci., 5: 362-369. DOI: 10.3844/jssp.2009.362.369 